\title{
A memória nacional lusitana em $O$ vento assobiando nas gruas, de Lídia Jorge
}

\section{The national lusitanian memory in $O$ vento assobiando nas gruas, by Lídia Jorge}

\author{
Clenir da Conceição Ribeiro ${ }^{1}$, Eliana da Conceição Tolentino ${ }^{2}$
}

\begin{abstract}
Resumo
Este trabalho tem como objetivo um estudo da obra $O$ vento assobiando nas gruas (2007), da escritora portuguesa Lídia Jorge. O romance metaforiza, por meio da protagonista Milene Leandro, a nação lusitana, pós-Revolução dos Cravos (1974), que oscila entre a grandiosidade do império e as transformações decorrentes desse acontecimento. Milene, diagnosticada com oligofrenia - doença que consiste na interrupção do desenvolvimento da inteligência - pode simbolizar uma nação com memória fantasiosa que lida mal com o passado beirando o esquecimento. Além disso, em um diálogo com a história do período colonial português, intentamos um estudo da memória nacional e seus desdobramentos com a descolonização. Para a efetivação da pesquisa, recorreremos a teóricos, como Beatriz Sarlo (2007), Jacques Le Goff (2003) e Pierre Nora (1993) para problematizar a relação entre história e memória. Maurice Halbwachs (1990) para visitar a memória coletiva, bem como a Benedict Anderson (2005), Ernest Renan (2005), Bhabha (1998) e Wander Melo Miranda (2010) para abordar nação e Eduardo Lourenço (1998) para situar o contexto português pós-74.
\end{abstract}

Palavras-chave: Nação. Memória. História. Portugal.

\begin{abstract}
This research aims to study the Portuguese writer Lidia Jorge's book, O vento assobiando nas gruas. The novel produces a metaphor concerning the post Carnation Revolution (1974) at the Lusitanian nation through its leading figure, Milene Leandro. The metaphor tells since the changes caused by the event, until the majesty of the empire. Milene, diagnosed with Oligophrenia - it's a disease that hinders intelligence development - she could represent a nation without memory that mishandles its past, which verges on oblivion. In addition, in a dialogue within the Portuguese colonial period history, we attempt a national memory study and its deployments with the decolonization. The research dwells on theoreticians such as Beatriz Sarlo (2007), Jacques Le Goff (2003) and Pierre Nora (1993) for the problematization between history and memory, Maurice Halbwachs (1990) to visit collective memory. As well as Benedict Anderson (2005), Ernest Renan (2005), Bhabha (1998) and Wander Melo Miranda (2010) to approach the nation theme and Eduardo Lourenço (1998) to situate the post -74 Portuguese context.
\end{abstract}

Keywords: Nation. Memory. History. Portugal.

\footnotetext{
${ }^{1}$ Mestranda em Letras na Universidade Federal de São João del-Rei (UFSJ), São João del-Rei, Minas Gerais, Brasil. E-mail: clenir14@hotmail.com

${ }^{2}$ Doutorado em Letras pela Universidade Federal de Minas Gerais (UFMG), Belo Horizonte, Minas Gerais, Brasil. Professora Associada da Universidade Federal de São João del-Rei, São João del-Rei, Minas Gerais, Brasil. E-mail: elianat@ufsj.edu.br
} 


\section{Introdução}

Nação e memória são conceitos que estão, desde sempre, interligados, principalmente quando se trata da tentativa de reafirmar o sentimento de pertencer a uma comunidade imaginada. Conforme afirma o pesquisador Wander Melo Miranda (2010), a memória nacional, responsável por manter a coesão social e a estabilidade das instituições que delimitam as fronteiras nacionais, é a forma mais acabada da memória coletiva.

As narrativas que elegeram Portugal como uma comunidade imaginada levaram em conta o período colonial, em que o país lusitano contava com colônias em diferentes continentes. Se a colonização refletiu a imagem de Portugal como uma nação centralizada, reforçada no sonho do Quinto império - designado assim, pelo sonho do Padre António Vieira, segundo o qual Portugal consumaria a realização do reino universal para a purificação da humanidade - a despeito de questões econômicas e políticas, no período posterior à Revolução dos Cravos, de 25 de abril de 1974, esta visão foi abalada.

O pós-74, a consequente descolonização em África e o fim da ditadura Salazarista, resultou em uma produção literária significativa. Para Eduardo Lourenço era "como se nesse momento, quer dizer, depois de 75, entre 75 e 80, em Portugal, a consciência portuguesa, a imaginação portuguesa, o imaginário português quisessem desenhar um outro mapa" (LOURENÇO, 2004, p. 349).

Em diálogo com essa reflexão, Eliana Tolentino (2016) afirma que:

Tem sido via ficcionalidade que escritores portugueses fizeram e fazem a revisão histórica e memorialística construindo um país pela literatura. Constantemente, a literatura portuguesa põe Portugal em questão, para usar a expressão de Eduardo Lourenço, relê, reconfigura e constrói fatos da história portuguesa desde a navegação à Revolução dos Cravos (TOLENTINO, 2016, p. 64).
Lídia Jorge, autora de $O$ vento assobiando nas gruas (2007), entre outras obras, é uma escritora portuguesa que faz parte da geração que desponta literariamente neste período, ocupando, assim, um lugar de destaque no panorama da literatura lusitana. É importante destacar, também, a passagem de escritores portugueses por África. Dessa forma, conforme Eliana Tolentino (2017), tem-se que o trânsito, desde sempre presente no movimento de colonização e descolonização, aponta para uma postura crítica do escritor, considerando o novo desenho do mapa identitário da nação portuguesa. É o caso de Lídia Jorge que passou alguns anos em Angola e Moçambique, onde atuou como professora do Ensino Secundário, durante o último período da guerra pela libertação destes dois países. E foi de sua experiência em África que a autora produziu livros como "A costa dos murmúrios" (1988) e "O vento assobiando nas gruas" (2007).

Diante disso, este artigo visa empreender um estudo da memória nacional lusitana a partir de um recorte do romance $O$ vento assobiando nas gruas, de Lídia Jorge. No enredo, a protagonista Milene Leandro, jovem portuguesa, vai conviver com a família de emigrantes caboverdianos - os Mata - que residem na antiga fábrica da família Leandro. Ela é diagnosticada com oligofrenia, deficiência que consiste na interrupção do desenvolvimento da inteligência. Milene se apaixona por Antonino Mata e desse relacionamento surgem diversos conflitos. Assim, pretendemos uma leitura da condição de Milene como a possível metáfora de uma nação com memória fantasiosa, que lida mal com o passado, beirando o esquecimento, e dos desdobramentos de seu contato com os Mata como símbolo de uma memória coletiva que oscila entre o império e as transformações decorrentes da Revolução dos Cravos.

Para a efetivação dos objetivos deste trabalho recorremos à leitura crítica do corpus literário e um aprofundamento teórico, para embasamento analítico, em questões como colonialismo, póscolonialismo, história, memória e nação. 


\section{Percursos metodológicos}

Os teóricos Homi Bhabha (1998) e Stuart Hall (2004) afirmam que o pós-colonial procura uma ruptura com o discurso hegemônico colonial de supremacia do homem europeu-colonizador sobre os povos colonizados, considerando o hibridismo cultural que resultou desse processo, pois, na colonização, as sociedades colonizadoras e as colonizadas foram transformadas pela transculturação, impossibilitando um retorno às "culturas originais".

No entanto, o fim do colonialismo não rompe por completo com o imaginário de pertencimento e hegemonia, principalmente das nações colonizadoras, diante disso torna-se necessário refletir acerca da ideia de nação, das características e costumes que permanecem mesmo com o póscolonialismo.

Para Benedict Anderson (2005), o sentimento de nacionalidade se elabora na mentalidade dos indivíduos por meio do desejo de compartilharem vivências e memórias em comum. Assim, pensar o nacional seria como imaginar uma comunidade em que os membros se reconhecem como pertencentes a um determinado espaço temporal e físico que os une e os caracteriza.

Ampliando a abordagem de nação para além de fronteiras físicas, Homi Bhabha (1998), em O local da cultura, baseado em sua experiência diaspórica, afirma que a nação moderna é caracterizada pela "vontade de nacionalidade", que vai unificar a memória histórica e "assegurar o consentimento de cada dia" (BHABHA, 1998, p. 225).

Ademais, esse teórico salienta que a nação é um construto descentralizado, marginal, fronteiriço e que se recusa a acontecer de forma unitária, ou seja a nação é plural e necessita de ser reconhecida assim, embora as vozes dissonantes que a compõem pretendam soar de forma unissonante.

Dessa forma, Homi Bhabha reconhece que a nação não é linear, porém em sua abordagem ele "não nega a historicidade e suas implicações e ressalta que a sucessão de momentos históricos se entrelaça à liminaridade cultural, estado de um entre lugar, o qual pode ser associado à margem do nacionalismo" (CHAVES, 2014, p. 23).

A partir disso, é presumível ressaltar que a existência de fronteiras e pluralidade nas nações pós-coloniais colocam em choque a unidade pretendida pelos países colonizadores. Entretanto, considerando o contexto colonial como fortalecedor das hegemonias nacionais, para que uma nação seja consolidada como comunidade imaginada faz-se necessário que memória e história estejam alinhadas de modo que as diferenças culturais sejam negociadas. Diante disso, o passado assume um importante papel. Wander Melo Miranda (2010), em Nações literárias, ressalta que o passado está em constante ressignificação e sua importância para a nação se dá porque "uma nação não existe sem passado: é preciso lembrar a herança deixada por seus fundadores. A memória nacional [...] é a memória do monumento público, oficial, que se organiza em torno dos grandes acontecimentos e personagens históricos" (MIRANDA, 2010, p. 35).

Ele comenta também acerca da importância dos monumentos, principalmente os funerários, para a perpetuação da "comunidade imaginada", pois retratam a face canônica de uma nação e dá a ela "um espelho onde se mirar, embevecida ou orgulhosa de seu amor-próprio e pátrio" (p. 15). Também, afirma que, na memória nacional, os mortos veiculam-se aos vivos e aos que vão nascer, como se a história da nação emergisse de um passado imemorial.

Além disso, o pesquisador salienta que o "caráter fantasmagórico" das imaginações nacionais é difícil de ser desfeito, reafirmando a memória coletiva da nação que mantém os indivíduos unidos por partilharem lembranças em comum, mas que pode remeter à falta de compatibilidade entre os valores defendidos pela historiografia tradicional e as demandas do país, manifestadas em seus conflitos históricos e internos.

No entanto, ele afirma que "a narrativa da nação é um jogo sutil entre lembrar e esquecer", o que remete à discussão de Ernest Renan de que sem o esquecimento da violência existente na 
origem de todas as nações é impossível formar a unidade que as constitui. De acordo com Miranda:

A comunhão de interesses comuns pelos indivíduos é também partilha de coisas que devem ser esquecidas em conjunto ou lembradas, quando destrutivas, para que não se repitam, para que sejam constantemente "esquecidas". Raça, língua, religião e interesses militares submetem-se à abstração das diferenças e ao princípio do esquecimento de um dissenso primeiro (MIRANDA, 2010, p. 35).

Dessa forma, é plausível afirmar que a memória coletiva nacional é construída por grupos dominantes que mostram do passado apenas o que lhes parece relevante, e nas palavras de Ruben George Oliven:

A memória coletiva está ligada a um grupo relativamente restrito e portador de uma tradição, aproximando-se do mito e manifestandose através da ritualização dessa tradição. Já a memória nacional refere-se a uma entidade mais ampla e genérica (a nação), aproximandose mais da ideologia e, por conseguinte, estendendo-se à sociedade como um todo e definindo-se como universal (OLIVEN, 1992, p. 20).

No entanto, Miranda (2010) comenta que escrever as histórias das nações, atualmente, exige que se considere o "espaço-nação" marcado pela diferença cultural, que descentraliza o imaginário hegemônico e remete à existência de fronteiras internas. Porém, o autor menciona que quando as memórias silenciadas surgem, "iniciam-se operações de 'negociação' entre as diversas memórias, com o objetivo de manter a unidade social sempre renovada, embora tal procedimento não deixe de apontar para o fosso existente entre as reivindicações da sociedade civil e as imposições do Estado-nação hegemônico" (p. 37). Segundo ele, essas negociações aludem ao "plebiscito diário", usado por Ernest Renan na definição de nação, por reunir heranças do passado com um futuro a se realizar, por meio do desejo de continuar a viver em conjunto.
Diante disso, é evidente que história, memória e passado podem ser responsáveis por perpetuar ou levar ao esquecimento a formação nacional. Sobre a relação entre esses elementos, Beatriz Sarlo, em Tempo Passado: Cultura da memória guinada subjetiva (2007), salienta que:

O passado é sempre conflituoso. A ele se referem, em concorrência, a memória e a história, porque nem sempre a história consegue acreditar na memória, e a memória desconfia de uma reconstituição que não coloque em seu centro os direitos da lembrança (direito da vida, de justiça, de subjetividade). Pensar que poderia existir um entendimento fácil entre essas perspectivas sobre o passado é um desejo ou um lugar-comum (SARLO, 2007, p. 9).

Já o teórico Jacques Le Goff, em História e Memória (2003), ao discutir os inúmeros elementos que caracterizam os diferentes tipos de memória e sua relação com a história, aponta que o surgimento da escrita colocou a memória oral em conflito com os documentos. Desde então, a história passou a ser narrada sob a perspectiva de instituições de poder formais, elegendo o que deve ser lembrando quando se trata da memória coletiva, ou seja, os fenômenos da memória existem na medida em que são mantidos ou reconstituídos por uma organização, formada por indivíduos que dominaram e dominam as sociedades. Assim, os silêncios da história revelam os mecanismos de manipulação da memória coletiva.

Pode-se considerar que memória coletiva é, conforme definição de classificação de Maurice Halbwachs (1990), normativa e simbólica, porque neutraliza as contradições históricas assim como os conflitos sociais para selecionar do passado o que considera relevante para a coletividade. Os acontecimentos escolhidos são idealizados e a eles presente e passado se ligam, apontando-se para uma visão para o futuro. Logo, a memória coletiva não ultrapassa os limites do grupo dominante.

Além disso, é importante mencionar o papel da história na construção da memória nacional, pois segundo Pierre Nora (1993, p. 10), “a história, 
e mais precisamente aquela do desenvolvimento nacional, constitui a mais forte de nossas tradições coletivas; nosso meio de memória, por excelência".

No mais, é imprescindível mencionar que, conforme discutido por Hall (2004), as culturas nacionais são compostas por símbolos e representações que influenciam nas ações e na constituição dos indivíduos produzindo, assim, sentidos sobre a nação que constroem identidades e reforçam as histórias contadas sobre essa nação, o que conecta presente e passado.

Diante dessa contextualização, pode-se considerar que a memória nacional portuguesa foi construída baseando-se no imaginário de grandiosidade e hegemonia identitária e cultural, calcada no período colonial. Porém, "a descolonização configura-se traumática para Portugal" (TOLENTINO, 2017, p. 6049) e essa visão de centro é abalada. Assim, nesse contexto, surge a necessidade de se revisitar a memória e a história lusitana.

\section{$O$ vento assobiando nas gruas: um olhar sobre a memória portuguesa}

A localização histórica de um povo num espaço já vivido pelos seus antepassados e carregado de memórias compreende a nação como uma comunidade de gerações, ressaltando as emoções coletivas, os elementos gentílicos da nascença e da imaginação.

Portugal, durante um longo período, não se preocupou com a imposição de outras nações sobre o seu domínio e, mesmo sem poder econômico, o país manteve sua homogeneidade cultural e social.

No entanto, com a Revolução dos Cravos, e consequente descolonização em África, esse poderio se viu perturbado, uma vez que, conforme discute Boaventura Santos (1993, p. 45), Portugal por "seu caráter semiperiférico" não adotou um "neocolonialismo hegemônico" e "não pôde ou não quis controlar o processo da independência como fizeram as potências coloniais centrais, mas é também duvidoso que o pudesse controlar mesmo que o quisesse". Logo, pode-se afirmar que por questões econômicas e políticas a constituição da identidade colonial lusitana e a memória de tudo que ela representou foi abalada.

$\mathrm{O}$ enredo de $O$ vento assobiando nas gruas é uma possibilidade de simbolizar a oscilação da memória nacional portuguesa, porque o romance narra a união e os conflitos entre dois mundos, um contemporâneo envolvido com o futuro e outro mais antigo em que a história da Fábrica de Conservas Leandro se entrelaça à de cabo-verdianos em Portugal. E unindo-os está a protagonista Milene Leandro que será lida por nós como metáfora da nação portuguesa pós-Revolução dos Cravos.

No romance, Milene, devido ao seu diagnóstico de oligofrenia, "aos treze anos, era como se tivesse nove, aos quinze teria dez, às vezes cinco, às vezes treze e subitamente ostentava a sua verdadeira idade [...]. Aos vinte anos, teria uns quinze" (JORGE, 2007, p. 457), tenta encontrar as palavras certas para explicar aos tios o fato de o corpo de sua avó, Regina Leandro, ter sido encontrado na entrada da antiga fábrica da família, nessa busca ela acaba por se envolver com emigrantes africanos da família Mata que ali residiam e se apaixona por Antonino, operador de gruas.

A morte da matriarca Regina, símbolo de poder e manutenção da harmonia para os Leandro e responsável por Milene, desperta na protagonista a necessidade de se ter responsabilidade e ser ouvida pelos tios.

Queria contar por palavras seus todos esses trâmites, porque no fundo desejava ser senhora duma situação que a si mesma, mais do que qualquer outra pessoa, dizia respeito. Mas pretendia contar tudo, com a segurança da pessoa adulta que era, e não como se fosse a espécie de criança por quem a tomavam. Pois ela não tinha nem dez nem doze, nem vinte anos tão-pouco, sentindo-se pelo contrário uma rapariga inteiramente responsável, e a prova é que ali havia andado naquela marcha, para trás e para diante, à procura da avó, um fio de cabelo, um lenço de assoar, um tubo, um frasco, ou mesmo uma folha ou um ramo quebrado, qualquer coisa que explicasse o sucedido, ou pelo menos o confirmasse (JORGE, 2007, p. 13). 
Apontamos a possível leitura da passagem acima como metáfora da nação portuguesa contemporânea que para se reconstruir frente ao contexto globalizado precisa se desvincular do saudosismo colonial, revistar as memórias do período de ditadura Salazarista e o trauma pela luta de libertação das colônias, porque a hegemonia colonial já não é mais suficiente para representar as inúmeras vozes que formam o nacionalismo.

Milene também desejava recorrer a testemunhos para narrar o acontecido, conforme defendia seu primo João Paulo. E ela busca essas palavras na figura do padre que celebra o funeral, nos funcionários da ambulância e, principalmente, na fábrica desativada de sua família, agora habitação dos cabo-verdianos.

Sugerimos, assim, a leitura de A Fábrica de Conservas Leandro 1908, também, como símbolo da memória lusitana. Milene vai até ela em busca de explicações sobre a morte da avó, pois lá era considerado o "diamante" da família e o lugar que rememorava prosperidade.

Quando os restos da fábrica são colocados à venda para um grupo de holandeses, pelos Leandro, a família orgulha-se em falar das memórias do que fora o estabelecimento, sendo recorrente em diversos trechos do romance as lembranças da magnificência da fábrica.

Dessa forma, ela pode aludir à metáfora de uma nação que celebra a memória calcada no imaginário de grandiosidade de Portugal anterior a 1974. Além disso, a busca de Milene por fatos que justifiquem a morte da avó para contar aos tios pode remeter a fragilidade das memórias pós-74 diante do sistema imperial, mesmo a grandiosidade da fábrica sendo apenas lembrança.

Pondo de lado a sua santola, o tio explicou, com a cabeça fria, como em meados dos anos 70 tinha havido a possibilidade de se escrever nas paredes velhas frases como a fábrica a quem a trabalha, e abaixo os que nos exploram, e como fora assim que se tinha criado uma segunda vaga, uma segunda horda (JORGE, 2007, p. 267, destaque da autora).
O trecho ao lado reproduzido foi lido por nós como uma referência à Revolução dos Cravos (1974), momento que põe em questionamento a memória da nação portuguesa - representada pela fábrica - e expõe as novas configurações sociais, marcada pela existência de fronteiras internas, simbolizadas, principalmente, pela chegada de emigrantes e retornados em Portugal. Assim, a fábrica perde a sua função de monumento homogeneizador da nação.

Além disso, o aparente abandono em que a instituição se encontra, exemplificado pela perda de letras na inscrição frontal restando apenas "servas 1908", reforça a decadência da memória colonial. E quando passa a ser habitado pelos africanos, o antigo estabelecimento deixa de ser um marco que enaltece a memória e passa representar "ameaça".

No romance, Milene se confunde em relação as suas lembranças, imaginações e os fatos realmente vivenciados.

$\mathrm{Na}$ sua memória, porém, naquela noite, os lugares do presente e do passado iriam aparecerlhe completamente entrançados, e por isso tinha demorado muito tempo a separar aquilo que a avó vestiria àquela data e o que a avó havia usado, vinte e cinco anos atrás, quando Milene ainda era uma criança de pouca idade. Difícil distinguir. Com as luzes todas abertas, os armários escancarados, tinha percorrido, sem cessar os dois pisos de Villa Regina, vasculhando objectos em todas as direcções do considerável espaço daquela casa. E sem dar conta, amanhecia o domingo dezessete de Agosto, pois, de repente, no meio de tanta gaveta aberta, já era outro dia. Não fazia mal. Depois dessa azáfama, Milene iria poder escolher o mais necessário. Mas, quanto às palavras para explicar o sucedido, não as tinha (JORGE, 2007, p. 21).

O trecho recortado é uma possível referência ao esquecimento da nação portuguesa pósRevolução dos Cravos do discurso que se construiu de Portugal como uma pátria hegemônica e centralizada, uma vez que, com a descolonização, o país não se firmou como potência.

Em acréscimo, essa posição da protagonista pode simbolizar também a urgência de se revisitar 
a história e memória portuguesa, pois o contato com os colonizados já havia transformado a visão de centro de Portugal. Assim como a emergência de construção de uma memória lusitana heterogênea, que mescle o passado glorioso e as transformações oriundas da transculturação. Desse modo, podese considerar que Portugal tem sua constituição histórica e memorialística fora de suas fronteiras externas e internas.

E se a colonização configura-se como marco fundador da memória nacional lusitana, a descolonização e seus desdobramentos é traumática para o país português, embora seja mais ainda para as colônias, porque sua situação periférica em relação a Europa desconstrói o imaginário político e cultural de centro, trazendo à luz do contexto globalizado a exploração portuguesa praticada no colonialismo.

Eduardo Lourenço (1998) analisa a imagem nacional sempre irrealista que os portugueses têm de si mesmos. Ele afirma que Portugal necessita de uma "cura psicanalítica" (1998, p. 16) que o faça reencontrar consigo próprio, permitindo-lhe passar, definitivamente da infância para a vida adulta: "O que é necessário é uma autêntica psicanálise do nosso comportamento global, um exame sem complacências que nos devolva ao nosso ser profundo ou para ele nos encaminhe ao arrancarnos as máscaras que nós confundimos com o rosto verdadeiro" (LOURENÇO, 1998, p. 16).

No romance, Milene, devido à oligofrenia e à relação que desenvolve com os Mata mesmo sabendo da opinião de sua família de que eles eram a "terceira leva", não tem em si as marcas de uma suposta superioridade lusitana e colonial sobre outros povos e etnias, nem o sentimento de fracasso em vista do fim do sistema imperial e tudo que ele representou. Nesse contexto, ela reflete o posicionamento, mesmo tímido, de desejo de "arrancar as máscaras" que caracterizam a nação lusitana.

No entanto, sugerimos a leitura de que o fato de Milene ser silenciada, pelos tios, também aponta para a vontade de permanência do imaginário de centro. Em inúmeras passagens, ela é ignorada quando quer dar seu ponto de vista acerca da morte da avó.

O tio falava, no meio do living room da avó Regina, apressado, como era o seu hábito. Tinha despido o casaco e, quando passara pela primeira vez junto da tia Ângela Margarida, havia-lho pendurado nas mãos. As costas bem lançadas de Rui Ludovice apareceram na sua amplidão. Ficou em camisa. Ficou marron. 'Vamos aos factos'. 'Que factos, tio?' Milene queria falar. O tio poderoso não queria ouvir? Ele não respondeu. Sem casaco, dirigiu-se para as portas que davam para o jardim da nogueira e escancarou-as, com ruído. (JORGE, 2007, p. 125 , destaque da autora).

$\mathrm{Na}$ narrativa, quando os tios decidiam o que fazer com a herança de Regina Leandro, Rui Ludovice questionou, como se Milene não participasse do encontro, "E a garota?". Essa questão silenciou a todos, até que:

\begin{abstract}
'Um momento' - Rui Ludovice tinha pressa. O juízo rápido e perfeito, livre dos sentimentos que prendiam os outros à inacção. 'Um momento'. Por todas as razões e mais alguma, a Milene precisa ficar aqui. Precisa de ter responsabilidade por si mesma. Precisa acima de tudo de regularidade e continuidade na sua vida (JORGE, 2007, p. 127, destaque da autora).
\end{abstract}

Nesse trecho, levantamos a hipótese que pode ser observada a dificuldade de apagamento da ideia de comunidade imaginada de Portugal, porque os tios, símbolos do colonialismo, parecem decidir com autoridade pelo destino de Milene, metáfora da nação pós-74, uma vez que ela representa a possibilidade de ruptura de uma memória consolidada e a tentativa de escrita de novas versões.

A convivência dela com os cabo-verdianos e seu caso amoroso com Antonino Mata, como já discutido, também pode ser visto como uma proposta de pôr em análise a construção hegemônica da memória e história portuguesa.

No entanto, a dificuldade de se repensar Portugal é reforçada, no romance, nas atitudes dos 
Leandro. Diante do amor entre Antonino e Milene, a tradicional família vê sua história e interesse em vender a um grupo de holandeses a antiga fábrica ameaçados. Então, a tia Ângela Margarida, esposa do presidente da câmara, opta por submeter a jovem oligofrênica a uma laparoscopia, tendo o consentimento dos demais Leandro e sem que Milene e os Mata soubessem: "E já com o Sol escondido, Ângela Margarida convenceu a irmã a convencer a sobrinha de que seria útil passar pela clínica, agora que tinha decidido ter uma vida de mulher normal" (JORGE, 2007, p. 425).

Uma bissectriz que passasse pela continuação do diamante em nossas mãos, até ver, sem nenhum de nós perder nada. Pela ligação de Milene aos Mata, tal como ela deseja, respeitando todos os princípios humanitários que sempre foram próprios da nossa família, sem tocarmos no nosso bom nome. Pelo contrário, a bissectriz sustentaria todas as partes, de um lado e de outro, sem ferir nenhum de nossos princípios (JORGE, 2007, p. 448-449).

O fato mantém a fronteira entre o que é o português e o que é o africano, pois mesmo havendo o casamento, contato entre colônia e metrópole o emigrante será sempre o outro, bem como a nação parece desejar a permanência de sua homogeneidade, traço característico do colonialismo. E para permanecer o imaginário de unidade, as decisões são tomadas pelo grupo que detém a tradição.

Então é assim. Vamos supor que se percebia que Milene, por exemplo, não poderia ter filhos. Era ou não era possível traçar esta bissectriz? [...] Em geral, a regra é as mulheres serem férteis e os pretos serem prolíferos. Iria haver uma ninhada de mestiços na família Leandro. [...] "Escuta, Ângela Margarida - Tu capaste-a". "Capaste ou não capaste?" "Tu capaste-a!" [...] Por agora, o que ela queria era que compreendessem que não se pode recolher dignamente um proveito se não se participa na tarefa que o prepara. Era indecente distribuir um bem sem fazer partilhar do mal que ele implica (JORGE, 2007, p. 452).
Assim, consideramos que o crime contra Milene, metáfora da nação portuguesa contemporânea, tenta resguardar a memória colonial portuguesa ao impedir que no futuro ela fosse narrada por um indivíduo híbrido, fruto da protagonista e de Antonino. Dessa forma, a classe dominante, metaforizada pela família Leandro, continua a ditar e escrever a memória coletiva nacional, eliminando as diferenças.

Diante do ocorrido, a família Leandro, precisando que a fábrica fosse desocupada pelos cabo-verdianos a fim de ser vendida, mas temendo a má repercussão pública, devido ao amor entre Antonino e Milene, e o comprometimento com o cargo de presidente da câmara, de Rui Ludovice, decide apressar a união oficial do casal e, por meio de um advogado, apresentar aos Mata a seguinte proposta: "O que é preciso é vocês voltarem ao Bairro da Lata como os outros. Depois, uma vez lá, o Presidente dá um jeito. Não digo que sejam os primeiros a ocupar as habitações sociais, mas os sétimos ou oitavos serão". (JORGE, 2007, p. 473).

A morte trágica de Ana Mata, matriarca dos cabo-verdianos, foi um acontecimento que pode ter propiciado a continuação do poder de decisão nas mãos do Leandro.

O que eu soube depois, é que as coisas tinham mudado. - Começou com a presença do tio Rui Ludovice, presidente da câmara, no funeral de Ana Mata, e não só ele. [...] Esse fato foi muito notado e deu algum alento à família Mata, sobretudo às mulheres. [...] Depois veio o recado. O holandês Piet van de Berg não era só um homem disposto a respeitar as aves, as galinhas sultanas e as garças brancas com suas boinas de penas. Sempre que possível, também respeitava os seres humanos. Isto é, dava mais dois meses para a família Mata se refazer (JORGE, 2007, p. 478).

E vendida a fábrica, Rui Ludovice precisava decidir sobre a preferência da família Mata na lista para obter as casas sociais e se seria visto como duro ou piedoso para com as pessoas próximas da família: “[...] Pensaram, pensaram, e concluíram que seria muito mais humano, muito melhor aceite 
pela população de Valmares, genuinamente portuguesa, que a caridade começasse pelos que são mais próximos" (JORGE, 2007, p. 479).

A corrupção política dos Leandro disfarçada de benevolência na negociação com os Mata e a violência contra o corpo de Milene podem ser analisadas como a insistência dos moldes coloniais, mesmo no contexto pós-Revolução dos Cravos, em que a sociedade portuguesa é formada por africanos, portugueses, retornados e a nação não se espelha mais como potência.

Além disso, ressaltamos que o romance metaforiza o importante papel do esquecimento do passado e das violências na construção da memória nacional, pois ao receber a moradia a família Mata, antes arrasada com a desocupação da fábrica, "haviam entrado nas casas novas sorrindo. Nunca mais iriam pensar em Ribeirinho da Praia. Sentiam-se seguras" e o tio Rui "ainda não havia sido criticado por nada que se lhe relacionasse" (JORGE, 2007, p. 479). Assim, o consenso, mesmo conflituoso com a história, leva à constituição da memória coletiva pelo grupo dominante que, por operações de negociação, silencia os outros.

Ao término de $O$ vento assobiando nas gruas, Antonino Mata desconfia do que tinha sido feito a Milene na clínica, sendo a cirurgia de esterilização, e procura Rui Ludovice para se esclarecer alegando desejo de vingança. O tio da protagonista se pronuncia:

Eu não sei o que se passou, são coisas de mulheres, e de médicos e de chafurdadores do corpo humano, essa cambada... Mas eu não sei o que se passou. [...] e se você se quer vingar, pois vingue-se... Olhe eu não sei de nada, mas o que lhe posso dizer, em primeiro lugar, é que, se eu fosse você, no seu caso, primeiro eu pensaria muito bem. [...] você tem duas portas. Tem a porta da vingança, por onde você entra e fica satisfeito consigo mesmo, [...] no entanto, atrás dessa porta, você abre-a e só existe o abismo. [...] Pelo contrário, se você reserva, e entra através da outra porta, a da prudência, você salva os seus três filhos, a sua mãe, as suas tias e todos os seus irmãos de caírem no abismo... Você salva a própria Milene de cair no abismo. [...] Com a segunda, você salva todos e até pode salvar os seus irmãos que andam sob o olho da polícia, e sobretudo salvar-se a si mesmo, Antonino. Sim, porque, no meio de tudo, você é importante para você, Antonino... (JORGE, 2007, p. 490, 491).

Dessa forma, a atitude Rui Ludovice, a voz do poder, pode ser lido como uma impossibilidade de revisitar a memória silenciada, de Antonino, que seria indispensável na escrita da história da nação marcada pela diferença cultural e existência interna de fronteiras. Além disso, mais uma vez o discurso colonial, simbolizado pelo presidente da câmara, controla a negociação das diversas memórias para manter a unidade social.

No mais, o comportamento de Rui, assim como a ida dos cabo-verdianos - quando a fábrica é vendida - para o periférico Bairro dos Espelhos alude para as novas formas de colonização que os emigrantes são submetidos, ocupando as margens da cultura dominante.

A partir do estudo do romance corpus deste texto, sugerimos a possibilidade de a memória nacional portuguesa pós-74 ocupar um "não-lugar", caracterizado pela insistente tentativa de excluir o outro em prol da prevalência do imaginário de hegemonia construído durante o colonialismo, o que leva Portugal a uma provável crise identitária e cultural na contemporaneidade.

\section{Considerações finais}

A literatura portuguesa, posterior ao 25 de abril de 1974, empreende um processo de escrita em que as relações entre construção literária e contexto histórico se conectam intimamente.

O presente trabalho buscou empreender uma reflexão da memória da nação portuguesa com o fim do colonialismo a partir de recortes do romance $O$ vento assobiando nas gruas (2007), de Lídia Jorge.

Sobre a obra jorgiana, Raquel Trentin Oliveira afirma que: "Para a maior parte da crítica, o que mais chama a atenção na escrita da autora são suas estratégias narrativas inovadoras, a exploração meticulosa da linguagem e a maneira irônica com 
que problematiza o contexto sócio histórico atual" (OLIVEIRA, 2011, p. 114).

Pode-se ressaltar que o romance expõe as configurações sociais, em Portugal, no contexto pós-colonial, e enfatiza como os padrões de superioridade/inferioridade definem a relação entre colonizador e colonizado, silenciando as diferenças existentes na constituição da história e memória nacional.

Além disso, a presença de um narrador investigador, que intrigado com os segredos de sua família resolve levantar hipóteses sobre os acontecimentos, aponta para os variados pontos de vista de leitura dos fatos, como não sendo uma verdade incontestável. Presumimos que tal característica da narrativa pode remeter à necessidade de Portugal abandonar o discurso hegemônico colonial e (re) escrever sua memória nacional a partir da heterogeneidade pela qual é formado e através da revisitação da violência e exploração praticadas durante o colonialismo, mesmo que essa prática confronte a história já consolidada.

Ainda mais, consideramos ser possível observar que Portugal tem sua constituição histórica fora de suas fronteiras, porque as grandes navegações objetivavam a afirmação da supremacia cultural e identitária lusitana e não somente o poder econômico. Assim, o contato com os colonizados reflete na identidade portuguesa.

No entanto, parece que a memória nacional portuguesa, pela leitura crítica do romance, encontra-se alicerçada no que representou o período colonial. E as tentativas de se reconstruir a partir dos desdobramentos da Revolução dos Cravos são silenciadas para que a construção coletiva de grandiosidade e hegemonia advinda das grandes navegações continue a perpetuar.

\section{Referências}

ANDERSON, B. Comunidades imaginadas: reflexões sobre a origem e a difusão do nacionalismo. Tradução: Denise Bottman. São Paulo: Companhia das Letras, 2005.
BHABHA, H. Disseminação: o tempo, a narrativa e as margens da nação moderna. In: BHABHA, H. K. O local da cultura. Tradução: Myriam Ávila, Eliana L. L. Reis, Gláucia R. Gonçalves. Belo Horizonte: Ed. UFMG, 1998. p. 198-207.

CHAVES, A. M. M. Bárbara Eliodora, um bordado nacional. 2014. Dissertação (Mestrado em Letras) - Universidade Federal de São João del-Rei, São João del-Rei, 2014.

HALBWACHS, M. A Memória coletiva. Tradução: Laurent Léon Schaffter. São Paulo: Vértice / Revista dos Tribunais, 1990.

HALL, S. A identidade cultural na pósmodernidade. Tradução: Tomaz Tadeu da Silva e Guacira Lopes Louro. Rio de Janeiro: DP\&A, 2004.

JORGE, L. O vento assobiando nas gruas. Rio de Janeiro: Editora Record, 2007.

LE GOFF, J. Memória. In: LE GOFF, J. História e memória. Tradução: Bernardo Leitão, et al. Campinas: Ed. Unicamp, 2003. p. 419-476.

LOURENÇO, E. O labirinto da saudade: psicanálise mítica do destino português. Lisboa: Círculo de Leitores, 1998.

LOURENÇO, E. Divagação em torno de Lobo Antunes. In: COLÓQUIO INTERNACIONAL ANTÓNIO LOBO ANTUNES: A ESCRITA E O MUNDO EM ANTÓNIO LOBO ANTUNES, Évora, 2002. Actas [...]. Lisboa: Dom Quixote, 2004.

MIRANDA, W. M. Nações literárias; imagens da memória, imagens da nação. In: MIRANDA, W. M. Nações literárias. São Paulo: Ateliê Editorial, 2010. p. 15-24; 35-52.

NORA, P. Entre memória e história: a problemática dos lugares. Tradução: Yara Aun Khoury. Projeto História: Revista do Programa de Estudos PósGraduados em História do Departamento de História, São Paulo, v.10, p. 7-28, dez. 1993.

OLIVEIRA, R. T. O romance português contemporâneo e a apresentação de conflitos sociais: o vento assobiando nas gruas, de Lídia Jorge. Terra Roxa e Outras Terras, Londrina, v. 21, p. 113-124, set. 2011. DOI: 10.5433/1678-2054.2011v21p113. Disponível em: https://bit.ly/3mpMw0n. Acesso em: 30 nov. 2020. 
OLIVEN, R. G. A parte e o todo: a diversidade cultural no Brasil-Nação. Petrópolis: Vozes, 1992.

SANTOS, B. S. Modernidade, identidade e a cultura de fronteira. Tempo Social: Revista de Sociologia da USP, São Paulo, v. 5, n.1-2, p. 3152, 1993. (editado em nov. 1994). DOI: 10.1590/ ts.v5i1/2.84940. Disponível em: https://bit. ly/3fIeP8Y. Acesso em: 30 nov. 2020.

SARLO, B. Tempo passado: cultura da memória e guinada subjetiva. Tradução: Rosa Freire d'Aguiar. São Paulo: Companhia das Letras/Belo Horizonte: UFMG, 2007.

TOLENTINO, E. C. Retorno e retornados: um não lugar, um não estar. In: CONGRESSO INTERNACIONAL DA ABRALIC: textualidades contemporâneas, 15., 2017, Rio de Janeiro. Anais eletrônicos... Rio de Janeiro: ABRALIC, 2017. v. 4. p. 6049-6059.

TOLENTINO, E. C. A Revolução de abril: memória e ficção em Os memoráveis de Lídia Jorge. In: ASSUNÇAO, A. L.; BRAGANÇA, G. M.; FIGUEIREDO, I. V.; TOLENTINO, E. C. As letras da política. Rio de Janeiro: Mauad X, 2016. p. 6376. 
Ribeiro, C. C.; Tolentino, E. C. 